\title{
What in Fact is Fundamental Research in Business and Information Systems Engineering?
}

\section{DOI 10.1007/s12599-008-0024-1}

\section{The Authors}

Prof. Dr. Robert Winter

Universität St. Gallen

Institut für Wirtschaftsinformatik

Müller-Friedberg-Strasse 8

9000 St. Gallen

Schweiz

robert.winter@unisg.ch

Prof. Dr. Helmut Krcmar

Prof. Dr. Elmar J. Sinz

Prof. Dr. Stephan Zelewski

Prof. Alan R. Hevner, Ph.D.

This article is also available in German in print and via http://www.wirtschafts informatik.de: Winter R, Krcmar $\mathrm{H}$, Sinz EJ, Zelewski S, Hevner AR (2008) Was ist eigentlich Grundlagenforschung in der Wirtschaftsinformatik? WIRTSCHAFTSINFORMATIK. doi: 10.1007/11576-008-0130-1.

Business and information systems engineering (BISE) has established itself as a distinct sub-discipline "between" business sciences and computer science at least in the German-speaking countries. This primarily becomes obvious by two facts. First, the BISE section is one of the largest sections of the German Academic Association for Business Research (Verband der Hochschullehrer für Betriebswirtschaft e. V., VHB). Second, the BISE special interest group is the largest of the Gesellschaft für Informatik.

Nevertheless, in analogy to other "hyphenated" sub-disciplines it might be concluded from the positioning "between" business sciences and computer science that we are only dealing with an applied science that applies findings of its "reference" discipline computer science to companies and government agencies or vice versa applies findings of its "reference" discipline business sciences to informa- tion processing. This would consequently lead to the fact that not only necessary fundamental research would be limited to the "reference" disciplines, but also that public research funding, which is generally known to particularly focus on fundamental research, would have to be aligned accordingly.

Then again, there are various attempts to identify "theories", a "common body", or "core contributions" of BISE - e. g. by means of (modeling) methods as theories (Greiffenberg 2003), conceptual modeling as the discipline's core (Frank 1999), or support of integration (Heilmann 1989). Beyond the German-speaking countries, there are increasingly more attempts to consider the (IS) design process and its reflection as an autonomous core contribution (e. g. Hevner et al 2004) including theory development (e. g. Kuechler and Vaishnavi 2008) besides the social sciences-oriented reflection of IS development and usage.

Therefore, this discussion deals with the question whether fundamental research should be a part of BISE research and, if so, what its grounding is. The contributions particularly address the following issues:

- Should fundamental research be a part of BISE at all or is it a privilege of our "reference disciplines"?

- Is there a "common body" of BISE theories and, if so, which theories are included? Which role does or might modern organizational research play in this respect? Moreover, there is the question of the significance of system theory. Is it capable of providing at least a universal vocabulary for "integrating" the "reference disciplines"?

- Can the formalization of computer science help to describe and understand fundamental concepts in BISE?

- Which fundamental topics should BISE (continue to) address in future and to which (new?) fields of application may these fundamentals contribute?
My invitations to this discussion have been accepted by the following gentlemen (in alphabetical order):

- Prof. Alan R. Hevner, Ph.D, Citigroup/ Hidden River Chair of Distributed Technology, Information Systems and Decision Sciences, College of Business Administration, University of South Florida

- Prof. Dr. Helmut Krcmar, Chair of Information Systems, Department of Informatics, Technical University of Munich

- Prof. Dr. Elmar J. Sinz, Chair of Information Systems, especially Systems Engineering, University of Bamberg

- Prof. Dr. Stephan Zelewski, Institute for Production and Industrial Information Management, University of Duisburg-Essen

Helmut Krcmar emphasizes the importance of fundamental BISE research and claims to intensify research activities in this direction. He makes clear that an exclusive focus of design-oriented research on means-ends relations is not sufficient. Thus, it is important to consequently underpin the resulting research results also in a theoretical manner.

Due to the individuality of topic-goal combinations, Elmar J. Sinz votes for an application-oriented fundamental BISE research. He identifies the "evergreen topics" conceptual modeling, architectures, and design of business systems automation as central to such a fundamental research.

In his longer contribution, Stephan Zelewski sees the roots of BISE's fundamental research discussion in an identity and distinction crisis. In his opinion, one of the reasons is that design-oriented contributions are rejected by international or U.S.-American journals. Against this background he proposes to create BISE's identity-forming foundations by means of fundamental theories besides placing them in the epistemological "preliminaries". However, he doubts to what extent if at all - organizational and system the- 
ory may (exclusively) help. Instead he demands to avoid particular theories and turn towards a pluralism of theories. Furthermore, as for the kind of such theories, he discusses theories of formal languages. He concludes with a short discussion on how object-science research topics can be identified for BISE.

Just like Helmut Krcmar and Stephan Zelewski, Alan R. Hevner considers fundamental research as necessary for information systems research. In this context he attaches high importance to system theory and highlights complexity, composition/combination, and control as fundamental concepts. As regards each of these concepts he postulates the formulation of theories which allow for statements on scalability and efficiency of future information systems and which can also be verified empirically. Finally, he makes clear that we should revert to various research disciplines and paradigms in order to create these foundations because only in this way future challenges can be addressed.

These contributions make clear that fundamental research in BISE is not a question of "if" but "how". Besides the "return" to system theory there is the claim for an explicit pluralism of theories that needs further development in order to serve as consistent foundation.

If you would like to comment on this topic or another article of the journal Business \& Information System Engineering (BISE), please send your contribution (max. 2 pages) to Hans-Ulrich.Buhl@ wiwi.uni-augsburg.de.

Prof. Dr. Robert Winter Institute of Information Management University of St. Gallen

\section{References}

Frank U (1999) Conceptual modelling as the core of the information systems discipline - perspectives and epistemological challenges. Proceedings of the fifth Americas conference on information systems (AMCIS), Milwaukee, pp 695-697

Greiffenberg S (2003) Methoden als Theorien der Wirtschaftsinformatik. In: Uhr W, Esswein W, Schoop E (eds) Wirtschaftsinformatik 2003, Band II - Medien, Märkte, Mobilität. Physica, Heidelberg, pp 947-968

Heilmann H (1989) Integration: Ein zentraler Begriff in der Wirtschaftsinformatik im Wandel der Zeit. HMD 26(150):46-58

Hevner A, March S, Park J, Ram S (2004) Design science in information systems research. MIS Quarterly 28(1):75-105
Kuechler W, Vaishnavi V (2008) Theory development in design science research: anatomy of a research project. In: Vaishnavi V, Baskerville $R$ (eds) Proceedings of the third international conference on design science research in information systems and technology (DESRIST), Atlanta, pp 1-15

\section{Innovations as Prerequisite of Fundamental Research in BISE}

Due to its close contact with reality and its design orientation BISE is frequently called an applied science. Combined with this "clarification" it is often noted that corresponding fundamental research takes place in the reference disciplines, that is in economics, organization theory, computer science, just to mention few.

This contribution intends to show that this does by no means have to be true and that a self-confident BISE discipline requires and is able to do both applied and fundamental research. Accordingly, this contribution also aims at motivating towards more fundamental BISE research.

The term fundamental research does only make sense in dissociation of applied research. While the latter closely connects research activities to solving current problems of economic, social, or cultural practice, fundamental research focuses on explaining phenomena in nature and society without presuming a concrete application context. Fundamental research generates explanatory models for structures and coherences of a particular object of research. Fundamental research comes to an end with a satisfying explanatory model for the analyzed phenomenon. Applied research, in contrast, applies these models in order to develop a useful solution for a given and so far insufficiently solved problem.

These different objectives are not a genuine challenge of BISE. It adopted this divergence from business administration. Chmielewicz distinguishes theoretical research as a search for cause-effect relationships and technological research as a search for means-ends relationships (Chmielewicz 1979). To solve problems, the theoretical foundations in form of known cause-effect relationships have to be "applied" by transforming them into means-ends relationships.

Examining the relationship between these research levels more accurately, it becomes obvious that the object of research respectively design is also conceived dif- ferently. A critical-rational understanding of science (in the English-speaking world often equated with positivism) initially postulates a model of possible cause-effect relationships on a class of phenomena, e. g. the acceptance of new information systems in enterprises. These cause-effect relationships are then analyzed based on a set of corresponding instances, e. g. a survey on the acceptance of relevant actors in the company. However, research on a technological level usually starts with a so far poorly solved problem, e. g. piloting a virtual community for cancer patients. In order to determine useful means-ends relationships the design object's specific context has to be considered. The distinction of rigor and relevance can be traced back to these research concepts.

This outline of research concepts might lead to solely considering fundamental research on the theoretical level, i. e. linking it to the development of explanatory models and thus theories. Then, designoriented research would in any case be applied research, i. e. theories' cause-effect relationships are merely "translated" into means-ends relations. However, this is not sufficient.

Design-oriented research as a search for innovative solutions must be an essential component of fundamental research in BISE. With information systems being socio-technical systems, BISE has chosen a domain subject to rapid technological progress. This is primarily due to BISE's reference disciplines. With the goal of an "optimal provision of information and the support of communication according to economic criteria" (Wissenschaftliche Kommission Wirtschaftsinformatik 1994, p. 80) or the "reasonable full automation" (Mertens 1995, p. 48), BISE has to deal with the useful application of these new technological possibilities. However, the corresponding search for innovation as the core of design-oriented research leads to the fact that there is only limited access to the results of the theoretical level, simply because the intended applications of existing theories do no longer conform to the current parameters. Thus, the "theoretical underpinnings" are missing (Chmielewicz 1979, p. 182). Therefore, scientifically penetrating a new phenomenon does not begin at the theoretical level but should begin within design-oriented research (see Witte 1997). Only here concepts and constructs necessary for theoretical research can be identified or developed respectively. 
However, an autonomous fundamental BISE research requires to consistently transfer the results of design-oriented research to the theoretical level. The newly identified goal-means relationships have in fact been developed without an adequate explanatory model. A major task of theoretical research now consists in identifying the cause-effect relationships underlying the means-ends relationships. Examples can e.g. be found at Briggs (2006) or the design theories (e. g. Gregor and Jones 2007).

However, at this point the challenges of an integrative perspective on explanation- and design-orientation become clear. It is mandatory to thoroughly deal with the notion of theory. Pragmatic proposals, such as the design theories, are no more than the first step and can rather be seen as an effective communication tool.

The fact that BISE is able to combine explanatory and theoretical contributions at the applied and fundamental level imposes greater challenges on researchers than the so-called "uniparadigmatic" sciences. Thus, existing theoretical models of explanationoriented research, such as the structuralist approach, have to be adapted to the specific requirements of design-oriented research. Moreover, it would have to be sorted out which role artifacts of design-oriented research, particularly conceptual models as representations of problem solutions, can or should play in such an integrated understanding. Likewise, the methodical requirements have to be transferred to the advancement of the methodical canon.

If this is understood, close contact with reality, transdisciplinarity about a common theoretical understanding, and the already existing methodical pluralism constitute outstanding competitive advantages for German BISE.

Prof. Dr. Helmut Krcmar Chair of Information Systems Department of Informatics Technical University of Munich

\section{References}

Briggs RO (2006) On theory-driven design and deployment of collaboration systems. Int J Human-Computer Studies 64(7):573-582

Chmielewicz K (1979) Forschungskonzeptionen der Wirtschaftswissenschaft (Band 92), 2nd edn. Poeschel, Stuttgart

Gregor S, Jones D (2007) The anatomy of a design theory. J Association for Information Systems (JAIS) 8(5):312-335

Mertens $\mathrm{P}(1995)$ Wirtschaftsinformatik: von den
Moden zum Trends. In: König W (ed) Wirtschaftsinformatik '95: Wettbewerbsfähigkeit, Innovation, Wirtschaftlichkeit. Physica, Heidelberg, pp 25-64

Wissenschaftliche Kommission Wirtschaftsinformatik (1994) Profil der Wirtschaftsinformatik. WIRTSCHAFTSINFORMATIK 36(1):80-81

Witte $E$ (1997) Feldexperimente als Innovationstest - Die Pilotprojekte zu neuen Medien. Zeitschrift für betriebswirtschaftliche Forschung 49(5):419-436

\section{Fundamental Research in BISE - Towards a Position Determination}

A scientific discipline requires fundamental research of its own if the foundations of neighboring and reference disciplines are not sufficient to achieve the desired scientific objectives. This in turn means that the respective discipline has to be sufficiently distinguishable from neighboring and reference disciplines, and thus bears characteristics of autonomy. The autonomy of BISE basically has not been questioned for decades (Heinrich et al. 2007, p. 13).

\section{BISE as an autonomous scientific discipline}

In essence, a scientific discipline is defined by its object of research, its (scientific) objectives, and its methods and procedures. BISE shares its object of research with business administration as a first approximation: the enterprise or its suband super-systems such as divisions or groups, or in general business systems in economy and administration. Regarding its objectives, BISE differs from business administration. While the objectives of business administration are geared to economic activities in accordance with the principle of rational economics (Wöhe and Döring 2008, p. 1 ff), BISE's objectives refer to information processing in business systems. Of course, the latter are also subject to the principle of efficiency. Nevertheless, at this point the differences to business administration become clear: BISE's objectives focus on the analysis, design, and management of business information systems. BISE's object is a company's information system as a business system's information processing subsystem (Ferstl and Sinz 2008, p. 1 f).

The autonomy of a scientific discipline is generally justified by the tuple (object, objectives), which in case of BISE suffi- ciently differs from business administration. However, the methods and procedures employed are not considered when assessing autonomy (Heinrich et al 2007, p. 13). Instead, a discipline has to be open-minded with respect to choosing methods and procedures to achieve its objectives. BISE traditionally draws from the methodic pool of economic sciences, especially business administration, as well as particularly from that of computer science whose object and objectives are aligned to computer-supported information processing. As business information systems constitute socio-technological systems, methods of system theory, cybernetics, organization science, work science, cognitive sciences, psychology, and sociology are added and will probably gain increasing importance in future.

\section{Fundamental BISE research}

In a narrow interpretation, fundamental research is pure and exclusively serves the purpose of multiplying knowledge, while applied research aims at the practicality of findings to solve concrete application problems. This narrow interpretation of fundamental research can probably be applied to just a few disciplines. Most likely, fundamental research, which by the way always bears the possibility of failure, in most disciplines focuses on more or less specific fields of application, which are not necessarily concrete applications. Even the German research association (Deutsche Forschungsgemeinschaft, DFG), which is traditionally committed to fundamental research (Deutsche Forschungsgemeinschaft 2008, p. 31), has been supporting knowledge transfer to economic and social usage in all funding processes for several years. Fundamental research in the field of BISE can basically be characterized as application-oriented fundamental research. Its objective is to develop basic theories, methods, and procedures for analyzing, designing, and managing business information systems. This often involves the integration and advancement of knowledge from the reference disciplines business administration and computer science. Accordingly, fundamental research usually can be carried out usefully only in cooperation with the reference and neighboring disciplines (for cooperation with computer science see Jarke 2009). 
Important fields for fundamental BISE research are (according to the author's subjective viewpoint):

- Conceptual Modeling: The aim is to develop basic methods and procedures for reconstructing business matters and activities as models which support analysis and design of information systems. As in many disciplines, models constitute one of the most important methodical tools also in BISE.

- Architectures: The complexity of business information systems requires basic and methodically well-founded knowledge for structuring and managing these systems' architectures and for architecture-based integration of subsystems. Current sub-fields are enterprise architectures and service-oriented architectures.

- Design of business systems automation: At this point one has to remember that in business administration IT systems are often conceptually seen as "mechanic" tools for conducting human tasks. Conversely, in computer science business information systems are often considered from the perspective of an application field for IT systems - BISE as an (the largest) applied computer science. Regarding BISE's object and objectives, both views are not sufficient. Specific fundamental BISE research is necessary in order to create theories and models for automating business systems. In this case the investigation of the human-computer interface including insights from e. g. work science, organizational theory, cognitive sciences, psychology, and sociology gain particular importance. BISE exhibits a remarkable constancy in addressing these research fields since the beginning of its existence. This is in line with the findings of a Delphi study (Heinzl et al.2001) according to which questions on architectures and the control of information systems complexity as well as humanmachine interfaces belong to the major scientific objectives for the next three or ten years. In contrast, "trends" within BISE as analyzed by Mertens (2006) tend not to be related to issues of fundamental research.

\section{Conclusion}

Alongside applied research, BISE as an autonomous discipline is also bound to fundamental research. Therefore it is necessary on the one hand to be aware of lines of research consistent in the long run and on the other hand to be innovative, open-minded, and flexible with respect to the chosen methods and procedures. The discipline's broadness should be perceived as an opportunity rather than lead to ideological struggles. Curiosity in research must not be restrained by a standardized assessment of research output.

Prof. Dr. Elmar J. Sinz Chair of Information Systems, especially Systems Engineering University of Bamberg

\section{References}

Deutsche Forschungsgemeinschaft (2008) Perspektiven der Forschung und ihrer Förderung 2007-2011. Wiley-VCH, Weinheim

Ferstl OK, Sinz EJ (2008) Grundlagen der Wirtschaftsinformatik, 6th edn. Oldenbourg, München

Heinrich LJ, Heinzl A, Roithmayr F (2007) Wirtschaftsinformatik. Einführung und Grundlegung, 3rd edn. Oldenbourg, München

Heinzl A, König W, Hack J (2001) Erkenntnisziele der Wirtschaftsinformatik in den nächsten dre und zehn Jahren. WIRTSCHAFTSINFORMATIK 43(3):223-233

Jarke M (2009) Perspektiven der Wirtschaftsinformatik aus Sicht der Informatik. WIRTSCHAFTSINFORMATIK 51(1)

Mertens P (2006) Moden und Nachhaltigkeit in der Wirtschaftsinformatik. Arbeitspapier Nr. 1/2006, Universität Erlangen-Nürnberg, Wirtschaftsinformatik I

Wöhe G, Döring U (2008) Einführung in die allgemeine Betriebswirtschaftslehre, 23rd edn. Vahlen, München

\section{What in Fact is Fundamental Research in BISE?}

For some time, German-language BISE seems to be suffering from an identity and distinguishing crisis. ${ }^{1}$ The reason for this crisis probably is the increased

\footnotetext{
In the course of this contribution for the section "BISE - Discussion" it may be excused that the author is not able to present "balanced" and accordingly "differentiated" arguments in due brevity, but tends to use formulations in a simplistic manner instead which sometimes are even "provocative". They are particularly meant to stimulate dialogue and, in particular, opposition. Moreover, the author concedes in advance that he primarily focuses on business administration so that he is only able to give an evaluation of BISE from his role as an "interested fence guest". These arguments can never be "representative" or "appropriate" judgments such as from the pen of an insider who is deeply rooted in the scientific BISE community.
}

international competition as regards publications, which is mainly staged on the "market" of leading U.S.-American IS research journals. Spurred by education politicians' and technocrats' specifications saying that German research in general - and thus German BISE in particular - has to improve its international "visibility", there is significant pressure to obtain increased access to the journals mentioned above. This especially applies to young scientists whose chances for a career in real academia significantly depend on how many publications they can place in such journals, possibly even in one of the notorious "triple-A-journals".

In this context, it is considered painful that German-language BISE scientists often have to experience to be rejected with their research by the editors and reviewers of the leading U.S. IS research journals because their contributions supposedly or actually - do not reflect the state of the art. In German-language BISE, one widely shares the conviction that the IS research community features an unreflective and one-sided scientific orientation which clearly prefers quantitative empirical analyses "scientifically" inspired by "models" of natural scientific research, also called "the scientistic fallacy". Contributions of German-language BISE, often bearing design and evaluation orientation (design of software prototypes and evaluation of their pros and cons under business application conditions), are hardly thought to have any chances on the international, in particular the U.S.-American, publication market against this background.

An initial response to this situation diagnosis is a radical adjustment to the practices, in particular the epistemological "specifications", of U.S.-American IS research. This radical adjustment strategy leads to the expectation of success in terms of international "visibility", but means losing the identity of an independent German-language BISE. Therefore, in large parts of German-language BISE another alternative as second answer to the "international", that is in fact U.S.American, challenge is pursued. This alternative answer is to emphasize basic research in BISE. Basic research, which is from an epistemological perspective not only but especially broader (particularly more pluralistic) and deeper than IS research, is supposed to provide Germanlanguage BISE with an independent identity and help to distinguish itself from IS 
research. The latter is felt to be "restricted" to quantitative-empirical research and to be superficial seen from an epistemological perspective. The following arguments are solely based on the second answer's perspective.

If one approves the previously outlined point of view, fundamental research in (German-language) BISE should by no means be left to its reference disciplines such as computer science and business administration. Instead, fundamental BISE research constitutes a welcome means which may significantly foster the establishment of identity and distinction from the competing IS research. In addition, BISE representatives should not hope that computer science and business administration will explore the foundations of particular interest to BISE's objects of experience and knowledge, e. g. with respect to modeling languages and reference models. It remains BISE's genuine task to explore these foundations and not only to deal with "applied" - and thus third party funded - research.

Sharing the opinion that BISE should be in charge of its own fundamental research, we must then ask the question about such a fundamental research's scope. This question cannot be finally answered by a "fence guest", but has to be subject of the discourse between scientists of that field. From the perspective of an outsider there are basically two different approaches. However, these do not have to compete but can also be complementary.

On the one hand, fundamental BISE research may be located within the epistemological "preliminaries", which are (have to be) made in the so-called basic area of any science. Much has been written elsewhere on BISE's scientific-theoretical fundamentals. These mainly include ontological, epistemological, and methodological basic decisions. In this respect, BISE can distinguish itself internationally by not unilaterally focusing on a quantitative-empirical methods ideal, which often appears combined with a seemingly naive epistemological realism, but also admitting alternative scientific positions. In particular, BISE can develop an autonomous identity by means of an epistemological pluralism and thus set itself apart from the method-centered monism of IS research.

On the other hand, one may try to create BISE's identity-establishing fundamentals by means of a "common body of theories".
This would require a small set of fundamental theories, which prove to be sufficiently "abstract" or "general" in order to represent a common theoretical basis for the broad diversity of BISE's - primarily applied - research contributions. Often system theory and organizational theory are frequently mentioned as candidates for such a theoretical basis. The author is extremely skeptical of these experiments to identify such a "mandatory" theoretical foundation for BISE. Essentially, two reasons support this skepticism.

First, there are considerable doubts as to whether both of the above mentioned theories are suitable for a "common body of theories" for BISE. Strictly speaking, "the" organizational theory does not exist at all. Instead it splits into multiple competing theory variants which usually differ significantly in terms of their ontological, epistemological, and methodological basic decisions. Given such heterogeneity neither "the" organizational theory as a whole nor a particular variant may serve as an identity-forming theoretical foundation of BISE. In fact, "the" system theory does not constitute a consistent theory either. But there is at least a system-theoretical vocabulary which conjointly underlies most of "the" system theory's variants. Advantageously, it is located on such a high level of abstraction that is applicable to a wide variety of object-science objects of experience and knowledge. In addition, system theory constitutes a structural science from a scientific theory perspective. It can be applied to all sciences of reality that engage in "understanding" relevant sections of reality with the linguistic possibilities of system theory. Therefore, system theory can possibly at least in terms of its vocabulary be considered as a unifying, identity-forming foundation of BISE. However, one may utter serious concerns for this intention, which can only be presented in short here. On the one hand, it is questionable whether the system-theoretically established vocabulary is sufficient to cover "all" of BISE's objects of knowledge. This is because system theory is bound to a "thinking and reasoning pattern" focusing on concepts such as elements, attributes of elements, and relationships among elements. This particularly allows describing the structure of systems in a linguistically comprehensive way. However, these concepts offer little potential for dealing with other situations in an equally elegant and comprehensive way. On the object level, these include, for example, processes ("business processes"), which are executed in given system structures. On the meta level, these include languages which help modeling systems including their structures and processes.

Second, in the author's opinion it is basically inappropriate to strive after seeking a unifying, identity-forming foundation of BISE within particular theories. This is because every theory is connected with decisions ("preliminaries") in its basic area which a priori limit its potential of understanding. An open-minded and pluralistic BISE discipline distinguishes itself - even in deliberate differentiation against IS research - by the fact that no "preferred" theoretical foundations is defined a priori. Instead, multiple theories should compete. This competition of theories may particularly deal with generating explanations or offering "technological" knowledge. The former covers facts that are considered "interesting" or "problematic" and, e. g., have been put as "stylized facts" in the scientific community of BISE. The latter is about interdependencies that may be used for designing information and communication technology artifacts. From this explanation- or design-oriented perspective it would be inappropriate to define certain theories as "fundamental" for BISE. Instead, besides the pluralism of methods that is propagated by several BISE representatives, also a pluralism of theories must be claimed. This is because the competition among alternative theories is most likely expected to yield scientific progress by improved explanation or design achievements on a theoretical foundation.

Even if a focus on certain theories (or families of theory variants) is rejected in the interest of a pluralism of theories, it might be considered to recommend a certain kind of theories for BISE's identity and differentiation. These could especially be theories based on formal languages. The main reason for favoring this formalization is that, given the international dominance of IS research with its quantitativeempirical research design a priori focusing on quantification and thus formalization, comprehensive formalization of BISE research makes it most likely to achieve international resonance. The author confesses that he himself has a great liking for theories (largely) based on formal languages. Formalization of theories offers at least three important advantages. First, 
formalization is linked to the "salutary necessity" of stating what is actually meant in an explicit and precise manner - and not just drawing on formulations of natural language both ambiguous and fraught with meaning. Second, formal languages, such as e. g. predicate logic (1st order) as the lingua franca of scientific theory, bear the advantage of "international intelligibility". Thus, they are not subject to the "bias" that scientific contributions by non-English native speakers a priori have to deal with language barrier problems. Third, theories composed in formal languages can be compared much more easily with respect to progress or regress than it would be possible for theories formulated in natural language. Regarding this aspect of theory comparison, people mainly refer to the scientific-theoretical concept of the non statement view or structuralism, which allows for both a detailed and rigorous assessment of theories' progress or regress in so-called theory networks - up to determining the incommensurability of theories.

Despite these undisputable advantages of largely formalizing BISE theories, the warning should be given that theories composed in formal languages do not constitute a "remedy" for all pressing questions of BISE. On the one hand, serious scientific-theoretical arguments can be found for the conviction that all of a theory's "important" aspects can impossibly be expressed in a formal language alone. For example, this includes the need for using natural language correspondence rules (or equivalents) to reveal relations between a theory's formal language constructs and the "concerned" real facts from its intended field of application. Additionally, there are basic scientific-theoretical insights such as the Löwenheim-SkolemTheorem (Putnam 1980, pp. 464 ff; Quine 2003, pp. 75 ff; Stegmüller und von Kibéd 1984, pp. 222 ff, 264 f, 267 f, 440 f). These make it seem impossible to ever specify a theory's intended field of application by means of a formal language alone.

Finally, the question is raised what topics - possibly continuing current research topics - BISE should address to position itself promisingly within international competition, and how fundamental BISE research might contribute to dealing with such topics. The author feels unable to identify such topics. Here, Delphi studies, as repeatedly described in the Wirtschaftsinformatik journal, are much better suited. Or we might trust the foresight of "BISE-gurus" who are also known in the scientific BISE community. Both aspects will not be addressed in the following. Instead, the "meta level" question is raised on how object-science BISE topics can be identified that might be of particular interest for BISE's future development. The author recommends the scientific-theoretical concept of "stylized facts", which has already been briefly mentioned before.

"Stylized facts" are facts that abstract from contingent individual cases to an extent that they can be observed in many situations. At the same time they "reduce" the observation material to those aspects that are in need of a convincing explanation from a theoretical perspective and are not restricted to the interest of a special theory. Thus, on the part of fundamental BISE research it should be attempted to identify problem areas which do not only seem to be of interest within a specific theory but encounter greater feedback in the entire scientific community. Bibliometric analyses on relatively frequent research topics might give valuable insights in this context.

If BISE succeeds to agree on such a canon of "stylized facts", it would include a well-defined set of "researchable" objects. This would be welcome in two respects. On the one hand, it would be helpful to assess theories' progress or regress in order to relate their explanation or forecast potential to a common basis - the "stylized facts". On the other hand, Germanlanguage BISE would have a competitive advantage compared to its U.S.-American counterpart IS research. This is because in IS research almost every question - even if it is totally trivial - is examined with the "concentrated" instruments of quantitative empirical methods. In contrast, German-language BISE would distinguish itself by not considering an analysis to be scientifically important if it has been carried out with the established methodological instruments ("methods fetishism"). Rather, it would be recognized as a quality feature of German-language BISE that it primarily deals with those research questions that have been marked as being particularly interesting by means of a previous agreement on which "stylized facts" are worth research.

However, the author is not so naive to believe that an agreement on "stylized facts" worth research could easily be achieved in the German-language scientific BISE community. Instead, it may be expected that different "schools" of BISE - in the sense of "paradigms" according to Kuhn (Kuhn 2003; cf. also Feyerabend 1974; Hoyningen-Huene 1989) - insist on enforcing those topics as necessary "stylized facts" that correspond to their own research preferences. This scientific-sociological "provincialism" opposes a powerful presence of German-language BISE in international publication competition. However, this is another problem that has little in common with the aspects of fundamental BISE research discussed in this contribution.

Prof. Dr. Stephan Zelewski Institute for Production and Industrial Information Management University of Duisburg-Essen

\section{References}

Feyerabend PK (1974) Kuhns Struktur wissenschaftlicher Revolution - ein Trostbüchlein für Spezialisten? In: Lakatos I, Musgrave A (eds) Kritik und Erkenntnisfortschritt, Abhandlungen des Internationalen Kolloquiums über die Philosophie der Wissenschaft. London 1965. Vol 4. Vieweg, Wiesbaden, pp 191-222

Hoyningen-Huene P (1989) Die Wissenschaftsphilosophie Thomas S. Kuhns - Rekonstruktion und Grundlagenprobleme. Vieweg, Wiesbaden

Kuhn TS (2003) Die Struktur wissenschaftlicher Revolutionen. Special edition. Suhrkamp, Frankfurt am Main

Putnam H (1980) Models and reality. The Journal of Symbolic Logic 45(3):464-482

Quine WVO (2003) Ontologische Relativität und andere Schriften. Klostermann, Frankfurt am Main

Stegmüller W, von Kibéd MV (1984) Probleme und Resultate der Wissenschaftstheorie und Analytischen Philosophie. Vol III: Strukturtypen der Logik. Springer, Heidelberg

\section{What is "Fundamental/Basic" Research in Information Systems? - A Debate}

As my contribution to this debate I would like to propose that we rethink the scientific and engineering foundations of research in Information Systems (IS). We recognize that software-intensive information systems have revolutionized nearly every aspect of human life. Yet, a lack of science and engineering foundations and unpredictable operational environments leaves such systems at a high risk 
for failures, security breaches, and user dissatisfaction. We have reached a critical stage. While incremental improvements to existing ideas and designed artifacts provide some direction, research has not yet found a tipping point in which a new way of thinking can move the field forward in totally new and transformative directions. Bold new conceptualizations of systems are needed - from the basic concepts of design, evolution, and adaptation to advanced systems that seamlessly integrate human and computational capabilities. Emerging technologies, such as multi-core processors, pervasive and mobile computing, and autonomic applications (e. g., automated drug delivery systems and avionics landing control systems) heighten the urgency for new thinking.

One potentially radical approach for rethinking IS foundations is to start from a small set of intellectual drivers of systems thinking and then apply an in-depth understanding of these drivers to realworld problems via IS research. From my experience as a design researcher and consultant on many industrial projects, I find the following three system concepts to provide the most challenges and opportunities for transformative research in the IS field: complexity, composition, and control.

Managing complexity (technical, human, and societal) in the development, operation, and evolution of softwareintensive systems is an overriding challenge. Research to rethink IS complexity can be inspired by models in other scientific fields, both physical sciences and social sciences. For example, consider the development of IS artifacts that have the same robustness in the presence of complexity as biological organisms. Designing models and methods for managing complexity will require creative ideas for new information technology (IT) abstractions, representations, and languages.

Rethinking complexity will necessarily lead to changes in the way the qualities of IT artifacts are viewed. Current thinking assumes that if an accurate system specification can be produced up front then a system that fits stakeholder needs will naturally follow. Such an assumption is wrong when systems become complex enough to result in unexpected, emergent behaviors and properties in unstable operational environments. Software-intensive IS are subject to multiple stakeholders' inconsistent, contradictory, and partially understood objectives for behaviors and properties, such as performance, reliability, security, usability, and sustainability. While model-checking technologies have provided some useful forms of systems assurance, new ways of understanding and conceptualizing how IS qualities can be measured and evaluated are desired.

The essence of software-intensive IS design and evolution is composition of the system from component parts that may be developed by different parties in different languages and to different specifications. Mashups are examples of innovative approaches for composing disparate components of software and information. A composed system must interact properly with complex, uncertain environments, and the aggregate must be trusted. This concept requires that IS implementations respect the concerns of the domain, the intended usage, and the technology substrate (hardware and software) upon which systems execute. Successful identification of useful properties of IS must draw upon the relevant disciplines. We need new theories of abstraction, structuring, behavior and configuration as well as new logics for representing and reasoning about large systems in support of efficient and sustainable component-oriented engineering approaches. New theories of complexity and composition are needed to predict and reason about scalability in ways that can be empirically verified. A key challenge will be to identify perspicuous, useful, end-toend properties and models that span hardware and software technology platforms, the problem domain, user interaction, and context of use.

Control of IS has become increasingly challenging in situations of diverse software and data provenance, such as open source communities and dynamic supply chains. In such settings, requirements for dynamic composition have both human and automation aspects. Human cognition imposes limits on our abilities to design complex artifacts. New techniques to augment human intellectual control and coordination of the design, development and use of complex software-intensive IS are desired. For example, autonomic control of large-scale, distributed software-intensive systems can reduce or remove the requirement for human attention during runtime while still satisfying the needs of human users. Concepts of software system self-awareness and human-computer partnerships can lead to optimum system performance, negotiated access to resources, and novel IS configurations suitable to a particular situation. Research projects in this field might be inspired by emerging ideas in collective intelligence (e. g., wisdom of the crowds), virtual organizations (e. g., open-source user communities), and cognitive theories of abstraction, decomposition, and synthesis.

As we enter a future world of pervasive computing and ubiquitous cyberphysical devices it is essential that IT artifacts and the integrated systems containing these artifacts are reliable, adaptable, and sustainable. IS research must draw its foundations from multiple research disciplines and paradigms in order to effectively address a wide range of system challenges. Three of the most important intellectual drivers of future IS research will be dealing with complexity, composition, and control.

Consideration of these drivers must be the basis for the design of innovative artifacts and the development of rigorous theories to rethink the development, evolution, and adaptation of future information systems.

I gratefully acknowledge the many discussions with colleagues at the U.S. National Science Foundation that contributed to the formation of the ideas expressed herein.

Prof. Alan R. Hevner, Ph.D. Citigroup/Hidden River Chair of Distributed Technology Information Systems and Decision Sciences

College of Business Administration University of South Florida 


\section{WIRTSCHAFTSINFORMATIK \& MANAGEMENT

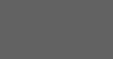

Test-Paket kostenlos lesen!

\section{Ausgaben}

"WIRTSCHAFTSINFORMATIK \& MANAGEMENT" und den 1GB USB-Stick gratis dazu!

\section{Gratis:}

\section{Ausgaben „WIRTSCHAFTSINFORMATIK \& MANAGEMENT"}

- Preis-Vorteil: 15\% Ersparnis gegenüber dem Einzelheftkauf

- Zeit-Vorteil: Sie lesen das Wesentliche übersichtlich und präzise und sind schnell besser informiert

- Wissens-Vorteil: Kurz und knapp von Praktikern für Praktiker

- Kompetenz-Vorteil: Die Zeitschrift erscheint im Gabler Verlag: Seit 75 Jahren, die Nummer 1 in Sachen Wirtschaft und Management

- Steuer-Vorteil: Sie können die Zeitschrift steuerlich geltend machen und lesen somit kostenlos

- Archiv-Vorteil: Abonnenten nutzen kostenlos das umfangreiche Online-Archiv

- Geschenk-Vorteil: Jetzt bestellen - USB-Stick gratis

\section{Gratis-Test-Gutschein Gutschein ausfüllen, faxen und sich auf einen 1GB USB-Stick freuen!}

\section{P}

JA, ich möchte 2 Ausgaben

"WIRTSCHAFTSINFORMATIK \& MANAGEMENT“ “

\section{+ den 1GB USB-Stick - kostenlos!}

Den praktischen 1GB USB-Stick* schicken Sie mir mit dem ersten Heft. Wenn mir "WRTSCHAFTSINFORMATIK \& MANAGEMENT" gefällt, brauche ich nichts weiter zu tun. Ich erhalte dann „WRTSCHAFTSINFORMATIK \& MANAGEMENT" fü mindestens 1 Jahr zum derzeitigen Vorzugs-Preis von nur 109,50 Euro (Ausland 117,50 Euro) inkl. Versand. Den Bezug kann ich jederzeit zur nächsten erreichbaren Ausgabe abbestellen. Zuviel bezahlte Beträge für nicht gelieferte Ausgaben erhalte ich zurück. Gefällt mir "WIRTSCHAFTSINFORMATIK \& MANAGEMENT" nicht, melde ich mich innerhalb von 10 Tagen nach Erhalt des zweiten kostenlosen Probeheftes schriftlich. (Ein Angebot der GWV Fachverlage GmbH, Geschäftsführer Dr. Ralf Birkelbach, A.F. Schirmacher, AG Wiesbaden HRB 9754.

Das Dankeschon und die Hefte darf ich auf jeden Fall behalten.

*Lieferung solange Vorrat reicht. Dieses Angebot gilt nur innerhalb der EU. 